\title{
Booster Bearing Failure Reduction Through a Novel Thermodynamic Analysis
}

\author{
Philip Venter (D) Martin van Eldik
}

Submitted: 5 May 2021/in revised form: 19 October 2021/Accepted: 9 November 2021/Published online: 2 December 2021

(C) The Author(s) 2021

\begin{abstract}
The gas booster station of a steel works has experienced excessive bearing failures since commissioning over two decades ago. This station was designed with redundancy, allowing for automatic switch-over between two gas booster fans. Bearing failures were observed, on average once every 15.7 days, with instances where both fans experienced simultaneous downtime. Booster failures resulted in regular station downtime, preventing Coke Oven Gas (COG) transport to an end user. This flammable by-product is used as a heat source and all unutilized volumes are flared, resulting in energy wastages. Furthermore, the absence of COG increases Natural Gas (NG) usage, procured at a cost. Traditional root cause analysis techniques failed to identify the cause of these excessive bearing failures. However, multiple in-depth data analysis studies resulted in a thermodynamic investigation, exposing liquid and solid particles within the COG to be responsible for the failures. This allowed for the design of an in-line particle collector, eliminating excessive failures. Following the particle collector installation, only two strategic bearing changes took place over the next 41 weeks, with reduced bearing vibration levels compared to before. The station experienced no failure downtime during this period, resulting in reduced COG flaring and thus improved energy utilization.
\end{abstract}

Keywords Bearing failures - Coke oven gas (COG) . Data analysis · Energy wastage $\cdot$ Natural gas (NG) · Thermodynamic root cause analysis

P. Venter $(\bowtie) \cdot$ M. van Eldik

North-West University Ringgold Standard Institution Engineering, Potchefstroom, North-West, South Africa e-mail: philip.venter@nwu.ac.za

\author{
Abbreviations \\ CFD Computational fluid dynamics \\ COB Coke oven batteries \\ COG Coke oven gas \\ HRP Hot rolling plant \\ NG Natural gas \\ $\mathrm{mm} / \mathrm{s} \quad$ Millimeter per second \\ $\mathrm{kW} \quad$ Kilo watt
}

\section{Introduction}

According to [1] maintenance expenses contribute 15 to $40 \%$ of manufacturing costs. It is also mentioned that the costs of breakdowns, especially bearing failures, are typically unknown. It is reported by [2] that improper bearing maintenance within the steel industry results in energy inefficient systems, and therefore, increased costs.

The steel industry consumes approximately $4.8 \%$ of the global energy. This industry typically wastes $48.0 \%$ of the energy in its processes, of which $5.4 \%$ is due to by-product losses. Therefore, improved energy utilization is an important aspect widely covered within this industry [3].

A steel works typically consists of various subsections and plants within its production chains. Associated with steel production, several flammable by-products are produced [4]. One such by-product is Coke Oven Gas (COG) originating from the Coke Oven Batteries (COB) [5]. Both $[6,7]$ reported that COG production contains fractions of impurities, that include small particles.

These impurities are mostly tar and naphthalene, where sulfides can also be present. Tar is collective for black viscous hydrocarbon liquids, obtained from a variety of organic materials. Scrubbers are installed to clean the COG 
of these impurities before it is utilized by other plants within the steel works [6-8].

Throughout the steel production industry COG is utilized as an energy resource $[3,5]$. Due to the intricate operational nature of a steel works, COG production cannot always be matched to its utilization. As a result, COG pipelines comprise a bleeder to regulate pressure by flaring excess supply. The downside of the bleeder is that continuous flaring is required to prevent air from entering the pipeline and mix with the flammable gas [9].

This paper provides an industry case study of an indepth data driven failure analysis regarding excessive gas booster bearing failures at a COG pipeline station. Identifying the failure's origin resulted in a structural mechanical design that prevents excessive future booster bearing failures and station downtime. Furthermore, this allows the steel works to save on maintenance costs, and more importantly, yielding both improved energy utilization through less COG wastages and overall safety.

\section{Problem Discussion}

For the steel works under consideration the discharge pressure at the $\mathrm{COB}$ is sufficient to reach all but two users. The one plant, which is near the COB, requires COG pressure above discharge. This plant comprises a gas booster station to increase pressure and operates without bearing difficulties. The other user is the Hot Rolling Plant (HRP) that also makes use of a gas booster station; however, a high frequency of bearing failures is observed.

The HRP is connected to the COB by a two-kilometer pipeline, so that a halfway gas booster station is required to increase the line pressure. This is to ensure that the COG line pressure at the HRP is above that of atmospheric conditions. At the HRP, thermal energy for production is acquired through combustion of COG with the addition of Natural Gas (NG) when required. Whereas COG is a byproduct, NG is procured per volume.

The halfway HRP gas booster station has two, 250 $[\mathrm{kW}]$, identical parallel rotating gas booster fans, from here on only referred to as boosters. Only one booster is operated at a time, with the second serving as backup when failure occurs. The backup starts automatically upon failure, or by manual switch-over during operations. Note, there is not a single booster dedicated as the primary or backup. The one in operation is by default the primary, and the other the backup. In theory the boosters should have no influence over the availability of COG at the HRP. This, however, is not the case.

Excessive booster bearing failures have been experienced since commissioning more than two decades ago. Above average vibration levels are typically detected during normal plant operations, and it is not uncommon for the backup unit to fail with start-up, or within a few hours thereafter. As a result, there are times when both boosters simultaneously require bearing maintenance. During these times the station's main inlet valve closes, increasing both NG usage and COG flaring.

It is important to note that the booster fan housings are sealed before both the drive and non-drive bearings. Therefore, neither of the bearings can be contaminated, or damaged, by the COG. Further note that all booster manufacturer and company protocols are followed during startup, so that this event itself should not influence the integrity of the bearing.

Throughout the previous two decades numerous root cause bearing failure analysis studies were undertaken. These studies followed scientifically based conventional failure analysis techniques; however, the root cause behind these frequent breakdowns could not be identified.

\section{Data Acquisition for Analysis Purposes}

Performing a successful failure analysis requires adequate and relevant data. Data are acquired that potentially comprise information, either directly or indirectly regarding the booster station. The data, to be discussed within this paper pertain to bearing pre-instalment, installation, operational and process conditions that relate to the bearings, boosters, and COG. Following acquisition, the technical interpretation of data is required to analyze the bearing failures.

Identifying the significance of bearing failures is comparable to the financial implication that results. From maintenance data it follows that the annual bearing maintenance costs amount to US Dollar (\$) 23,000. However, this is not the only financial implication as it was mentioned earlier that booster station shutdowns result in both increased NG usages and COG flaring.

A data analysis model was formulated to solve for annual excess NG procurements. This thermodynamic model includes hourly energy usages, COG production and flaring rates, together with line pressures simulations. The details of this model, however, do not fall within the scope of this paper. Modeling results indicate that excess annual NG procurements are in the proximity of $\$ 850,000$. Booster bearing failures, therefore, yield additional annual expenses in the order of $\$ 873,000$.

Note that $97.4 \%$ of the financial impact from booster bearing failures is typically due to NG expenses. If the bearing failures are not reduced but could at least be predicted in advance, so that preventive maintenance can occur, significant cost savings will be achieved. On-line condition monitoring is a well-known engineering practice 
used to predict bearing failures based on vibration analysis $[1,10]$.

\section{Condition Monitoring Incorporated as Preventative Maintenance}

Condition monitoring in terms of vibration analysis is an integral part in determining the operational health of a bearing [11]. Furthermore, condition monitoring can be used to plan maintenance in advance, and therefore, react proactive regarding possible bearing failures [10].

Figure 1 represents a typical condition monitoring graph for one of the boosters under investigation. Vibration measurements are represented by the fluctuating orange and darker blue trend lines for the drive- and non-drive end bearings, respectively. The vibration levels are provided on the y-axis in millimeter per second $(\mathrm{mm} / \mathrm{s})$. Time is given on the $\mathrm{x}$-axis from 2:00 AM to 7:00 AM. From plant personnel's experience it follows that the bearings should experience vibration levels closer to $10[\mathrm{~mm} / \mathrm{s}]$; however, historical data show that typical vibration levels around 20 $[\mathrm{mm} / \mathrm{s}]$ are observed. Note, it is common for the drive end bearing to experience higher vibrations, as depicted on the graph.

After 5:00 AM a slight increase in vibration levels is observed from Fig. 1 for both bearings. It is not uncommon for the bearings to experience slight increases and decreases during normal operations. Important to note, the vibration levels as depicted within this graph were observed over a sufficiently long period of time, where only a few hours are depicted in Fig. 1 for demonstration purposes. Based on the graph and this information, it is not necessarily possible to predict if the bearing will fail in near future, i.e., allowing planned proactive maintenance.

Further increases in the vibration levels can be seen from 7:00 AM onwards as depicted in Fig. 2. A bearing failure is observed (Fig. 2) in the proximity of 9:40 AM, whereafter the booster tripped. The black line is a representation of the electrical currents drawn by the unit, which can be seen decreasing to zero around 9:40 AM. Note from Fig. 2 how the vibration levels slowly increased prior to the bearing failure over a period of less than three hours.

Figures 1 and 2 represent a typical bearing failure where condition monitoring could not have been used to allow for preventative maintenance. Even though the failure was evident from 7:00 AM onward, realistically there was not an opportunity to plan a bearing change.

As mentioned earlier, upon failure the back-up booster starts immediately with practically no loss in COG transportation to the HRP. However, back-up booster bearing failures have resulted in numerous instances where the HRP could not receive COG. This resulted in higher NG usage at the HRP and increased unwanted COG flaring. Furthermore, regular bearing failures increase maintenance costs and reduce available artisan man-hours.

Data analysis indicates that failures are experienced, on average, every 15.7 days. As a result, bearing maintenance cannot be planned to eliminate booster downtime and reduce NG expenses. The problem can, therefore, not be overcome with preventative maintenance. The origin of the bearing failures needs to be identified. All available data and information are required to allow for a complete investigation.

\section{Failure Investigation and Prevention}

The following subsections pertain to the methodology articulated in solving the excessive bearing failures experienced at the halfway booster station. The methodology commences with a standard industry root cause analysis approach. Following this the process boundaries under investigation are increased when the bearing failure's origin is not identified.
Fig. 1 An operational graph indicating high bearing vibrations (orange and blue). (Color figure online)

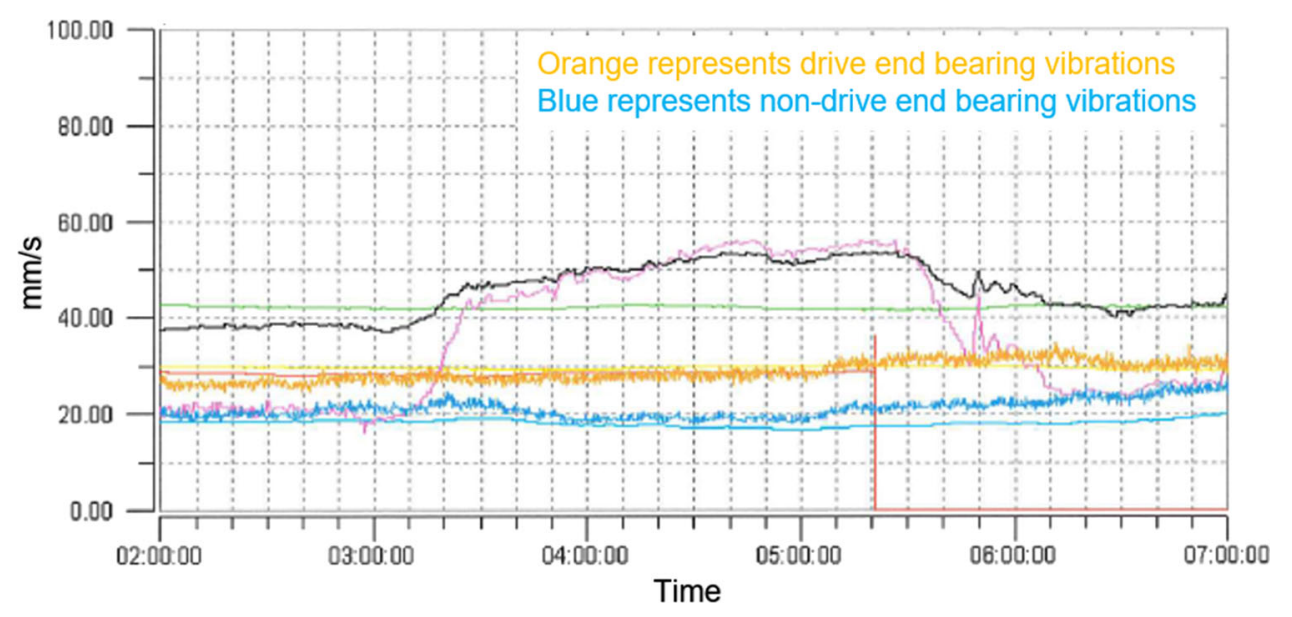


Fig. 2 An operational graph indicating high bearing vibrations (orange and blue). (Color figure online)

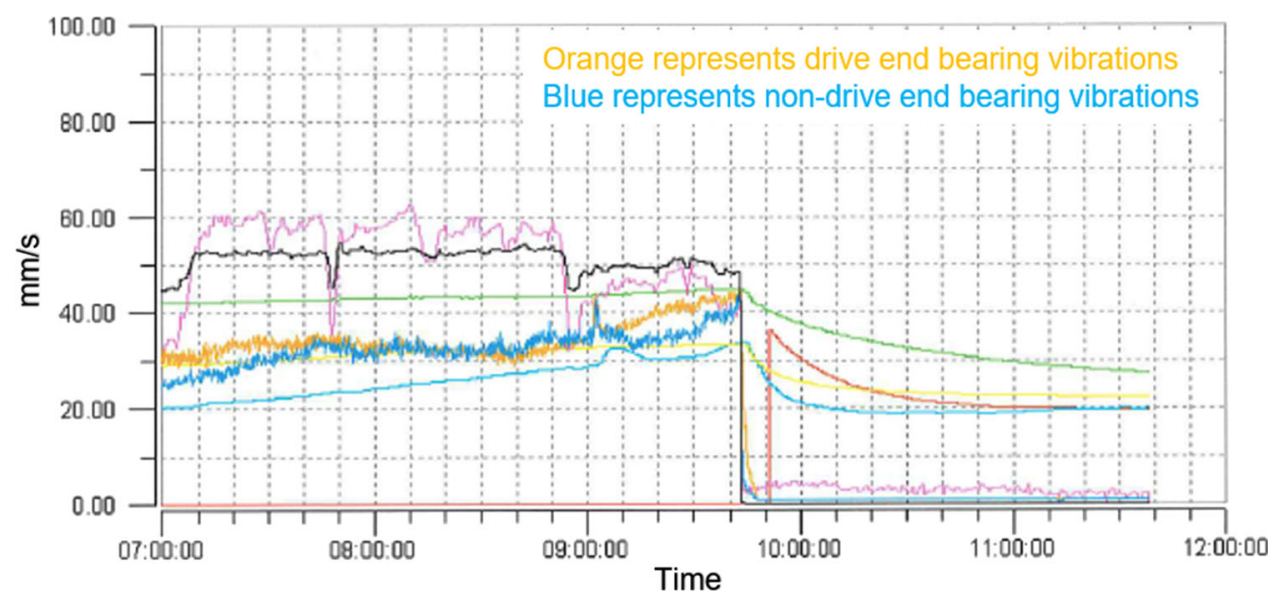

Standard Industry Root Cause Analysis Approach

A typical root cause analysis comprises data gathering and interpretation. Taking the booster bearings under investigation this will include component sizing, materials handling, installation and operations, together with operating conditions.

High quality equipment and craftsmanship are important considerations regarding bearing installations. An in-depth investigation showed that the bearings are of the highest industrial standard and correctly sized. It can, therefore, not be the cause of the frequent failures. Craftsmanship is also not at fault. The frequent bearing failures are not due to the installed equipment nor any craftsmanship incompetency.

Take note, for this paper craftsmanship includes the handling of bearings from procurement through storage and installation to maintenance in operation. Furthermore, maintenance includes continuous correct levels, and therefore quantity, of manufacturer's specified bearing lubrication.

Tribology specialists are part of the bearing installation process. Following each installation, the specialists ensure that both drive- and non-drive end bearings are aligned, and that the booster fan is balanced.

A data investigation shows that the boosters are operated at a constant speed and COG flows are never above the maximum, nor below the minimum ratings. Therefore, the bearings do not experience excessive operational loads from higher volume flows, nor low flows breaking away from the blades causing excessive vibrations.

Therefore, it can be concluded with sufficient certainty that following the installation procedure, the bearings and booster are in perfect working conditions. Furthermore, the booster is continuously operated within design specifications. In-depth investigations into the bearings and booster operational conditions do not provide any indication as to why these excessive failures are experienced.
It was reported earlier that higher-than-expected normal operation bearing vibration levels are present. Vibrations can be related to forces working in on the bearing, both radial and axial. Therefore, if higher-than-expected vibration levels are observed during normal operations, higherthan-expected forces acting on the bearing are present. From the elimination of all other possibilities, these unexpected booster bearing forces must follow from operational conditions.

\section{Frequency of Failures}

From a comprehensive failure analysis, it follows that winter months experience more frequent breakdowns, especially in short proximity of a start-up. The lubricating oil temperature is controlled between $28^{\circ} \mathrm{C}$ and $33^{\circ} \mathrm{C}$ with measurements logged every 5 minutes. Therefore, ambient temperatures should not influence the bearing directly. Logged oil temperature data indicate that control thereof is continuously within the operational limits.

It is important to note that summer months also experience failures, just not with the same frequency as winter times. Furthermore, the backup booster also fails more frequently in the winter months within proximity of a startup. Ambient temperature, therefore, influences the frequency of bearing failures, which prompts a thermodynamic investigation.

A thermodynamic simulation and analysis on the bearings only, will not result in further useful information, since it is bounded to the oil temperatures that are within a safe operational range. A broader thermodynamic investigation into the booster will, therefore, prompt a study of the fluid transported by it, i.e., COG. 
Thermodynamic-Based Failure Analysis

\section{Booster Operational Parameters}

The previous section highlighted those colder ambient temperatures increase the frequency of bearing failures. Important to note is that for the region extreme winter nights might drop below freezing, whereas daytimes are typically always above $0.0^{\circ} \mathrm{C}$. It was also concluded that force imbalances must act upon the booster fan during operations, inducing higher vibration levels.

Due to compressibility of gases, the COG can only yield force imbalances if either the flow breaks away from the rotating blades, or incompressible particles are present. Liquid or even solid particles will induce impact forces if contact is made with the rotating blades, i.e., impingement.

At the booster station inlet COG pressure and temperature are logged over fixed time periods. A prior measuring station logs the volume flow, temperature, and pressure. The measurements are used to calculate the mass flow in kilograms per second $[\mathrm{kg} / \mathrm{s}]$ for each time-period. There is no tie-off between the two measuring stations, so that from conservation laws it follows that the booster station mass flows are known.

The available data allow for a complete thermodynamic COG analysis to be performed. The density and viscosity are determined for all the measurement intervals and velocities calculated. From the results it follows that all thermodynamic parameters are within booster-design operating limits. Further calculations show that at no instance will the gas flow break away from the fan's blades to cause imbalance forces, and therefore, increase vibration levels.

A finite element analysis indicated that the boosters' rotating blades do not experience any significant stresses during its range of operations. As a result, no axial, nor radial forces due to passing COG should result in harmful vibrations. The design limitations of the boosters, can therefore, not be faulted.

\section{Ambient Temperature Influence on COG}

The influence of ambient temperature on COG is next investigated. The COG discharge temperature into the pipeline is approximately $88.0^{\circ} \mathrm{C}$. Both logged COG temperatures at the booster station and pipeline simulations indicate that the gas will not cool below $40.0^{\circ} \mathrm{C}$, which is typically when ambient conditions are at $0.0^{\circ} \mathrm{C}$. As mentioned, the surrounding environment rarely cools down below $0.0{ }^{\circ} \mathrm{C}$ during the coldest winter night. This requires the COG itself to be investigated around $40.0^{\circ} \mathrm{C}$.

Coke oven gas is not a homogenous substance and comprises several chemical compositions. Therefore, each individual chemical composition must be known, including individual mass or mole ratios. Table 1 provides the company's provided COG volume flow chemical compositions. Important to note, gas samples are analyzed at the company's Chemical analyses department on a frequent basis, not known to the authors. From the volume flows, the mole flows, and therefore, partial pressures are determined.

Each individual chemical composition in Table 1 is investigated. It follows that all these compositions are in a gaseous state at $40.0{ }^{\circ} \mathrm{C}$ under the respective partial pressures. Furthermore, Ethane $\left(\mathrm{C}_{2} \mathrm{H}_{6}\right)$ will be the first substance to condense at $-89.0^{\circ} \mathrm{C}$ under atmospheric conditions and comprise only $0.5 \%$ of the volume flow. The composition as provided in Table 1 will always be in a gaseous state at the booster station, allowing only gas to pass through the fan. The initial chemical analysis does not provide any additional information regarding forces acting on the booster blades or bearing failures.

It was mentioned earlier that the second booster station exists, near the COG for another plant, where no bearing problems are observed. This non-problematic booster station operates without frequent failures, with no difference observed between warmer (summer) and cooler (winter) months. The only difference between the two booster stations is that the non-problematic station operates at COG temperatures around $88.0^{\circ} \mathrm{C}$, the outlet condition of the COB. The two stations, therefore, operate under different thermal conditions.

\section{Thermodynamic Analysis of $C O G$}

The COG's thermodynamic analysis did not yield any useful information regarding the bearing failures. However, it was reported earlier [6-8] that COG production at the COB comprises a small fraction of solid particles, as well as tar and naphthalene $\left(\mathrm{C}_{10} \mathrm{H}_{8}\right)$ deposits. Mention was made that scrubbers are installed at a COB to remove these unwanted deposits (impurities). However, it is possible that

Table 1 The chemical composition volume flow (\%) properties of COG

\begin{tabular}{lc}
\hline Chemical composition & Volume flow percentage $(\%)$ \\
\hline Carbon dioxide $\left(\mathrm{CO}_{2}\right)$ & 2.8 \\
Carbon monoxide $(\mathrm{CO})$ & 5.1 \\
Ethane $\left(\mathrm{C}_{2} \mathrm{H}_{6}\right)$ & 0.5 \\
Ethylene $\left(\mathrm{C}_{2} \mathrm{H}_{4}\right)$ & 1.9 \\
Hydrogen $\left(\mathrm{H}_{2}\right)$ & 49.4 \\
Methane $\left(\mathrm{CH}_{4}\right)$ & 18.6 \\
Nitrogen $\left(\mathrm{N}_{2}\right)$ & 20.7 \\
Oxygen $\left(\mathrm{O}_{2}\right)$ & 1.0 \\
\hline
\end{tabular}


the scrubbers are failing to remove the solid or liquid particles

If the scrubbers do not remove all particles, a potential root cause to be investigated is whether impurities within the COG may influence the booster operations, and furthermore, the charge acting on the bearings. This will entail that the non-problematic booster station closer to the COB should also experience frequent failures and is therefore not necessarily a likely cause.

The melting point of tar is typically around $54.0^{\circ} \mathrm{C}$, and Naphthalene possesses a melting point of $80.3{ }^{\circ} \mathrm{C}$ [12]. Take note, if not removed by the scrubbers, both substances are in a liquid phase at the non-problematic booster station, and a solid phase at the problematic one. An investigation into the company's scrubbers revealed that these units are known to be inefficient and do not remove all liquid particles at $88.0^{\circ} \mathrm{C}$, i.e., tar and naphthalene. However, the non-problematic gas booster station operates at a temperature that exceeds the melting points of both substances, but small quantities of liquids will still be present. Furthermore, the impurities that are not removed should, volume-wise, be relatively small, otherwise the chemical analysis will pick up significant quantities.

Further investigation revealed that there is an annual budget to repair and replace identified sections of COG pipeline. Records indicate that there are always layers of solidified tar-like deposits within the pipeline. Furthermore, increased deposits (volume-wise) are found along the pipeline as the gas cools during transportation and it is not uncommon for a replaced pipe section to be filled more than half way with solidified particles.

From this it is evident that large quantities of solid deposits can be dislodged at any time, to pass through the booster. Important to note, these deposits are not found within the short (and warm) pipeline that connects the nonproblematic booster station.

It followed from plant personnel that tar deposits are always present at the problematic booster fan, when opened. These deposits are, however, not present at the non-problematic booster station. Even though some liquid tar quantities are transported through this non-problematic booster station, it is therefore concluded not to an extend that is harmful for the bearings.

For the problematic booster station of this study, seal drums are present along the one-kilometer COG pipeline to remove liquid and solid impurities. However, from the above mentioned these seal drums are not sufficient to remove impurities. From this information it is concluded that solid and viscous tar deposits, or impurities, are indeed present at the problematic boosters, whereas it is not present at the non-problematic booster station.

It can, therefore, be argued that these impurities collide with the problematic booster's impeller blades, inducing impact forces. Rather than small solid particles continuously colliding with the impeller blades, conglomerated quantities impact at discrete time events. Furthermore, due to the highly viscous nature of both liquid and especially solid tar, some deposits attach to the impeller as can be verified by plant maintenance personnel. These occurrences then result in both impact forces, as well as fan weight imbalances. Note that viscosity is indirectly proportional to temperature and therefore increases as the temperature decreases.

Both impact forces and blade imbalances will induce increased bearing vibrations. A significant impact force will result in an instantaneous vibration increase, depending on the size and position of collision. Blade imbalances due to viscous deposits attaching itself will result in gradual elevated vibration levels.

It was mentioned earlier that above average vibration levels are typically detected during normal plant operations, and it is not uncommon for the backup unit to fail with start-up. An important notice is that the booster plant on ground level, whereas the pipeline is elevated. The pipeline is vertically brought down toward the booster's inlet, whereafter it is vertically elevated to the same level of the inlet section. From the analysis results and information gained it can further be argued that tar deposits are likely present on the backup booster blades, at lower elevation, before start-up. This will result in higher vibration levels than expected at start-up that may even result in failure, depending on the imbalance forces exerted by these deposits.

Identifying the origin of the excessive bearing failures allowed to solve the two-decade old problem. Investing in adequate scrubbers would have sufficed but capital in the order of $\$ 10$ million was required. The company does not spend capital if the payback period falls outside a threeyear return on investment. Cladding is also not an option over the two-kilometer pipeline since this will result in maintenance difficulties when tracing corroded pipe sections. Cooling of gas will, furthermore, always occur at times when the HRP does not require COG. Another, localized cost-effective solution was therefore required.

To reduce booster bearing failures, energy wastages and excess NG utilizations, impurities within the COG need to be removed. An innovative solution was developed that entailed the design of an in-line impurity collector. The solution integrates thermal-fluid modelling with structural design. This structure will be referred to as the collector. The detail design of this collector, however, falls outside the scope of this paper.

By taking all the decision-making variables into consideration, a specific flow pattern was computed to separate the impurities from the COG. The collector is a vertical structure where COG enters near the bottom and exits on 
top. Impurities fall to the bottom and are collected in a seal drum below the collector.

Figure 3 depicts results from a computational fluid dynamics (CFD) simulation that was independently done to demonstrate the extraction of impurities by the designed structure. Due to the demonstrative nature of this figure, only impurities are displayed. Note that none of the exiting flow (vertically upwards) contains impurities. The technicality of this CFD simulation does not fall inside the scope of this paper and will be presented in future work, since it is only provided for demonstrative purposes.

The total cost including manufacturing and installation of the collector was below $\$ 200,000$ compared to $\$ 10$ million for scrubbers.

\section{Concluding Remarks Based on Implementation}

Following the impurity collector's installation, only two bearing changes occurred over the next 41 weeks, which included the entire winter. During all this time vibration levels were between 48 and 55\% lower than typical historic profiles. Furthermore, both bearing changes were strategic maintenance decisions and not due to failures. The innovative collector design resulted in zero booster station downtime, and therefore, reduced COG flaring, i.e., energy wastages.

During this time no excess NG usages occurred at the HRP, resulting in a monthly cost saving of approximately \$ 70,000. This means that the collector installation had a

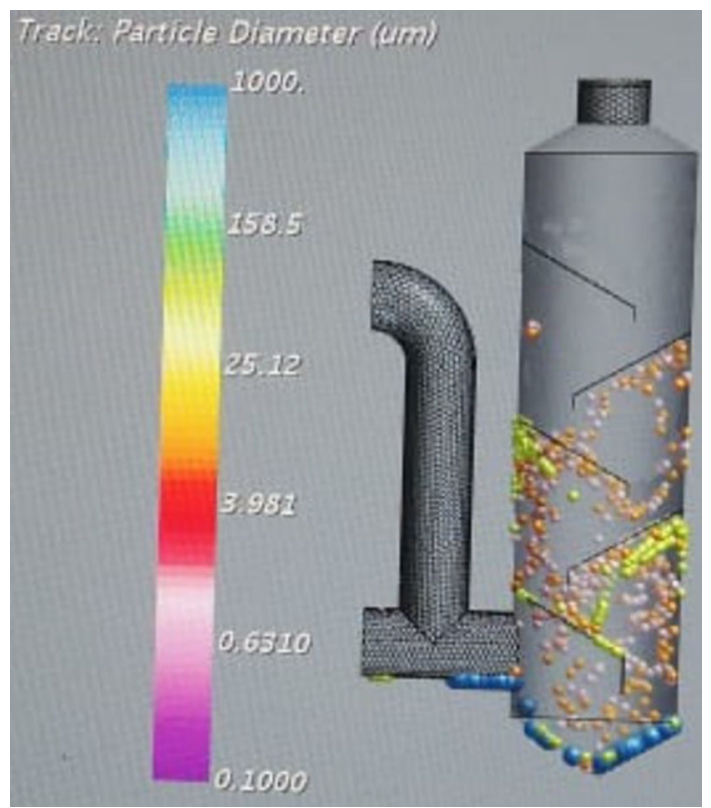

Fig. 3 A CFD simulation demonstrating the extraction of impurities within the COG during operation straight payback period of less than three months. From seal drum cleaning directly below the collector it followed that between 850.0 and $1300.0 \mathrm{~kg}$ of impurities were removed monthly, emphasizing the valuable contribution of this design.

This paper demonstrated how frequent mechanical bearing failures were resolved through a holistic problemsolving approach, incorporating data analysis with provided information. The process entailed an expansion of traditional bearing failure root cause analysis methods to include a chemical analysis of the gas compositions, together with a thermodynamic investigation. This allowed to solve for the bearing failure's origin, and in turn the excessive failures.

To conclude; a new, clearing, and innovative approach was incorporated within a complex field of a thermodynamic-based bearing failure analysis. Even though favorable results, the authors cannot generalize the outcome of this study, with some confidential company information that may not be provided. It is, however, believed that this may be a promising approach for future case studies.

Open Access This article is licensed under a Creative Commons Attribution 4.0 International License, which permits use, sharing, adaptation, distribution and reproduction in any medium or format, as long as you give appropriate credit to the original author(s) and the source, provide a link to the Creative Commons licence, and indicate if changes were made. The images or other third party material in this article are included in the article's Creative Commons licence, unless indicated otherwise in a credit line to the material. If material is not included in the article's Creative Commons licence and your intended use is not permitted by statutory regulation or exceeds the permitted use, you will need to obtain permission directly from the copyright holder. To view a copy of this licence, visit http://creativecommons. org/licenses/by/4.0/.

\section{References}

1. B.K.N. Rao, Handbook of Condition Monitoring, 1st Edition. Elsevier, Amsterdam (1996)

2. E. Worrell, P. Blinde, M. Neelis, E. Blomen, E. Masanet, Energy Efficiency Improvement and Cost Saving Opportunities for the U.S. Iron and Steel Industry

3. R.C. Gupta, Chapter 4.2-Energy Resources, Its Role and Use in Metallurgical Industries. Treatise on Process Metallurgy, Volume 3: Industrial Processes, pp. 1425-1458. Elsevier (2014)

4. Y. Yang, K. Raipala, L. Holappa, Chapter 1.1-Ironmaking. Treatise on Process Metallurgy, Volume 3: Industrial Processes, p. 2-88. Elsevier (2014)

5. R. Razzag, C. Li, S. Zhang, Coke oven gas: availability, properties, purification and utilization in China. Fuel. 113(2013), 287299 (2013)

6. D. Xiang, Y. Zhou, Concept design and techno-economic performance of hydrogen and ammonia co-generation by coke-oven gas-pressure swing adsorption integrated with chemical looping hydrogen process. Appl. Energy. 229(2018), 1024-1034 (2018) 
7. Q. Yi, G.S. Wu, M.H. Gong, Y. Huang, J. Feng, Y.H. Hao, A feasibility study for $\mathrm{CO} 2$ recycle assistance with coke oven gas to synthetic natural gas. Appl. Energy. 2017(193), 149-161 (2017)

8. J. Li, S. Zhang, Y. Nie, X. Ma, L. Xu, L. Wu, A holistic life cycle evaluation of coking production covering coke oven gas purification process based on the subdivision method (2020)

9. E. Németh, B.J. Seligmann, K. Hockings, J. Oakley, C. O'Brien, K.M. Hangos, I.T. Cameron, Generating case-implication graphs for process systems via blended hazard identification methods. Comput. Aided Chem. Eng. 29(2011), 1070-1074 (2011)
10. A. Soualhi, K. Medjaher, G. Celrc, H. Razik, Prediction of bearing failures by the analysis of the time series. Mech. Syst. Signal Process. 139 (2020)

11. C. Malla, I. Panigrai, Review of condition monitoring of rolling element bearing using vibration analysis and other techniques. J. Vib. Eng. Technol. 7, 407-414 (2019)

12. D.R. Lide, CRC Handbook of Chemistry and Physics, 90th edn. (CRC Press, Boca Raton, 2009)

Publisher's Note Springer Nature remains neutral with regard to jurisdictional claims in published maps and institutional affiliations. 